\title{
Control of the temporal interplay between excitation and inhibition by the statistics of visual input Jens Kremkow*1,2, Laurent Perrinet ${ }^{1}$, Cyril Monier ${ }^{3}$, Yves Frégnac ${ }^{3}$, Guillaume S Masson ${ }^{1}$ and Ad Aertsen ${ }^{2,4}$
}

\author{
Address: ${ }^{1}$ INCM, CNRS-Aix-Marseille University, Marseille, France, ${ }^{2}$ Neurobiology and Biophysics, University of Freiburg, Freiburg, Germany, \\ ${ }^{3}$ UNIC, CNRS, Gif-sur-Yvette, France and ${ }^{4}$ Bernstein Center for Computational Neuroscience, Freiburg, Germany \\ Email: Jens Kremkow* - kremkow@biologie.uni-freiburg.de \\ * Corresponding author
}

from Eighteenth Annual Computational Neuroscience Meeting: CNS*2009

Berlin, Germany. 18-23 July 2009

Published: 13 July 2009

BMC Neuroscience 2009, I0(Suppl I):O2I doi:I0.1 I86/I47I-2202-I0-SI-O2I

This abstract is available from: http://www.biomedcentral.com//47/-2202//0/SI/O2I

(C) 2009 Kremkow et al; licensee BioMed Central Ltd.

\section{Introduction}

In the primary visual cortex (V1), single cell responses to simple visual stimuli (drifting gratings) are usually strong but with a high trial-by-trial variability. In contrast, when exposed to full field natural scenes with simulated eye movements, the firing patterns of these neurons are sparse but highly reproducible over trials [1]. So far the mechanisms behind these two distinct different response behaviours are not yet fully understood. Different mechanisms are candidates for controlling spike timing precision and models are needed to clarify their respective contribution, which may be of thalamic or intracortical origin. As a first step, we investigated which aspects of the neuronal dynamics can be explained by balanced feedforward excitation and inhibition and its dependency upon the spatiotemporal statistics of the different stimuli. We built a simple model of the early visual system (LGN, V1). The thalamocortical connectivity was similar to the gpush-pullh architecture used in [2], with additional depressing thalamocortical synapses [3]. The model was written in PyNN [4] using NEST [5] as simulator. Indeed, the model can reproduce the main response characteristics of firstorder thalamo-cortical neurons in layer 4 of cat V1. During drifting gratings, excitatory and inhibitory conductances of cortical neurons were anti-correlated $[6,7]$, such that excitation can be freely integrated and induce multiple spikes. In contrast, during natural scenes the conductances were correlated, with inhibition lagging by few milliseconds $[1,8]$. This small lag between excitation and inhibition induces a strong selectivity to synchronous inputs, with a consequence that the responses became sparse and precise. However, some key aspects of the in vivo recordings in cat area $\mathrm{V} 1$ cannot be explained, such as selective reduction of stimulus-locked subthreshold noise during natural scene viewing, precise firing during fixational eye-movements and center-surround non-linearities, opening the door for future investigation about the role of intra-cortical recurrent connectivity in further shaping the neuronal responses to natural images. In conclusion, our study points that correlated inhibition can explain, at least in part, sparse and reliable spiking activity as observed in response to natural scenes. This is consistent with its role reported from other sensory modalities and cortical areas [8]. Thus correlated excitation and inhibition could be a general mechanism to induce sparse and precise spiking in the nervous system.

\section{Acknowledgements}

This work was supported by the CNRS, the Agence Nationale de la Recherche (ANR - Natstats), the 6th RFP of the EU (grant no. I5879-FACETS) and by the German Federal Ministry of Education and Research (BMBF grant 0IGQ0420 to BCCN, Freiburg).

\section{References}

I. Fregnac $Y$, Baudot $P$, Levy M, Marre O: An intracellular view of time coding and sparseness in $V I$ during virtual oculomotor exploration of natural scenes. Cosyne 2005:17. 
2. Troyer T, Krukowski A, Proebe N, Miller K: Contrast-invariant orientation tuning in cat visual cortex: thalamocortical input tuning and correlation-based intracortical connectivity. J Neurosci 1998, 18:5908-5927.

3. Banitt $Y$, Martin KAC, Segev I: A biologically realistic model of contrast invariant orientation tuning by thalamocortical synaptic depression. J Neurosci 2007, 27:10230-10239.

4. Davison A, Brüderle D, Eppler J, Kremkow J, Muller E, Pecevski D, Perrinet L, Yger P: PyNN: a common interface for neuronal network simulators. Front Neuroinform 2008, 2: II.

5. Gewaltig MO, Diesmann M: NEST (NEural Simulation Tool). Scholarpedia 2007, 2:1430.

6. Anderson JS, Carandini M, Ferster D: Orientation tuning of input conductance, excitation, and inhibition in cat primary visual cortex. J Neurophysiol 2000, 84:909-926.

7. Monier C, Fournier J, Frégnac Y: In vitro and in vivo measures of evoked excitatory and inhibitory conductance dynamics in sensory cortices. J Neurosci Methods 2008, 169:323-365.

8. Okun M, Lampi I: Instantaneous correlation of excitation and inhibition during ongoing and sensory-evoked activities. Nat Neurosci 2008, 1 I:535-537.

Publish with Biomed Central and every scientist can read your work free of charge

"BioMed Central will be the most significant development for disseminating the results of biomedical research in our lifetime. "

Sir Paul Nurse, Cancer Research UK

Your research papers will be:

- available free of charge to the entire biomedical community

- peer reviewed and published immediately upon acceptance

- cited in PubMed and archived on PubMed Central

- yours - you keep the copyright 